Research Article

\title{
Effect of Activity States on Habitat Selection by Black-Tailed Deer
}

\author{
SAMHITA BOSE, School of Biological Sciences, Victoria University of Wellington, PO Box 600, Wellington 6140, Nerw Zealand \\ TAVIS D. FORRESTER, ${ }^{1}$ Department of Wildife, Fish and Conservation Biology, University of California Davis, 1 Shields Avenue, Davis, CA \\ 95616, USA \\ DAVID S. CASADY, California Department of Fish and Wildlife, Large Mammal Conservation Program, 1812 9th Street, Sacramento, CA 95811, \\ $U S A$ \\ HEIKO U. WITTMER, ${ }^{2}$ School of Biological Sciences, Victoria University of Wellington, PO Box 600, Wellington 6140, New Zealand
}

\begin{abstract}
Habitat selection is a complex hierarchical process and in ungulates typically varies at broad spatial and temporal scales and among individuals. Recent advancements in the ability of global positioning system (GPS)-collars to collect activity data provide opportunities to understand underlying mechanisms or trade-offs responsible for fine-scale variation in habitat selection. Based on data from 64 female black-tailed deer (Odocoileus hemionus columbianus) fitted with GPS-collars in northern California, USA, between 2004 and 2013, we first investigated habitat selection at the home range scale. We then used data from a subset of 27 individuals to determine if habitat selection within home ranges was influenced by activity states (active or inactive). Habitat selection by black-tailed deer varied between summer and winter and was mostly explained by differences in elevation, terrain, and vegetation. Within their home ranges, black-tailed deer showed finescale selection for habitats that varied with activity states. In summer, selection for edge density and forest types varied across activity states highlighting important fine-scale selection patterns. Activity state also affected our conclusions about the selection of habitats including slope, canopy cover, and forest types by black-tailed deer in winter. During both seasons, deer selected for apparently secure habitat when inactive, likely to minimize risk of predation. These results highlight the importance of considering activity states when evaluating habitat selection from animal location data. This is particularly important in multi-use landscapes such as national forests where habitat needs of ungulates are important considerations in management decisions, including timber harvest. (c) 2018 The Wildlife Society.
\end{abstract}

KEY WORDS activity state, black-tailed deer, California, habitat selection, resource selection function, ungulates.

Habitat selection by animals is influenced by a range of conflicting demands associated with foraging (Hanley 1982), predator avoidance (Pierce et al. 2004, DeCesare et al. 2014), competition for mates and resources (Kie and Bowyer 1999), and rearing young (van Moorter et al. 2009). Habitats needed to meet these diverse requirements are often distributed heterogeneously in space and time. Selection of habitats by individual animals thus varies temporally to optimally use disjunct and clumped resources (Rosenzweig 1991, Morris 2003, Gaillard et al. 2010). The temporal variation in habitat selection can be short-term because of differences in circadian patterns (Ager et al. 2003, Prugh and Golden 2014), medium-term (e.g., seasonal) to account for variability in environmental conditions and physiological requirements (Long et al. 2009a, Monteith et al. 2011), or

Received: 2 October 2017; Accepted: 21 May 2018

\footnotetext{
${ }^{1}$ Present address: Oregon Department of Fish and Wildlife, 1401 Gekeler Lane, La Grande, OR 97850, USA.

${ }^{2}$ E-mail: heiko.wittmer@vuw.ac.nz
}

long-term (e.g., annual or even decadal) because of directional changes in demographic population structure and environmental parameters (Fryxell et al. 2008).

Ungulates, including mule deer (Odocoileus hemionus; Kie et al. 2002, D'Eon and Serrouya 2005, Sawyer et al. 2006), elk (Cervus canadensis; Boyce et al. 2003, Anderson et al. 2005, Sawyer et al. 2007), and caribou (Rangifer tarandus; Apps et al. 2001, Johnson et al. 2001, Rettie and Messier 2000, Leblond et al. 2011), select different habitats across spatial and temporal scales. Consequently, estimating habitat selection at fine spatio-temporal scales has been advocated (Ager et al. 2003, Mayor et al. 2009, van Beest et al. 2010). The hypothesis that habitat selection also depends on shortterm differences in behavioral states of individuals (Johnson 1980, Senft et al. 1987) has until recently remained largely unexplored (Roever et al. 2014) because of lack of technology linking location data used to quantify habitat selection to activity information (Wilmers et al. 2015).

Activity patterns of ruminating ungulates are composed of alternating foraging or walking (active states) and resting bouts used for mastication and digestion (inactive states; 
Gillingham et al. 1997). Although locational data can be used to estimate patterns of habitat selection, without a behavioral context these data may fail to capture changes in selection associated with daily foraging and resting patterns (Godvik et al. 2009, Roever et al. 2014). Overlooking activity states associated with habitat selection may lead to oversimplification of specific habitat requirements. Oversimplification would likely reduce the predictive power of pooled resource selection models and diminish the effectiveness of management strategies (Garshelis 2000, Roever et al. 2014). The use of habitat during active foraging and walking bouts and resting periods can also be affected differently by changing energetic demands, predation risk, and competition (Krebs 1980, DeCesare et al. 2014). Accounting for activity state in selection models may thus allow greater insights into the effects of these processes on ungulates.

Black-tailed deer (O. h. columbianus) are among the subspecies of mule deer and inhabit complex forested habitats in coastal areas from northern California into the Pacific Northwest and British Columbia. An important social and economic species in the western United States, they have been studied across their distribution (Heffelfinger and Messmer 2003). However, recent declines in blacktailed and mule deer populations throughout much of their ranges (Forrester and Wittmer 2013) has led to renewed interest in understanding habitat selection and resource use by the species to aid in developing effective management strategies.

Using resource selection functions (RSFs; Manly et al. 2002), we investigated fine-scale (i.e., within home ranges) habitat selection by black-tailed deer in northern California and tested how selection varied with activity states (active and inactive). Based on previous research (Kuhfeld et al. 1988, Bunnell 1990, Godvik et al. 2009), we hypothesized that black-tailed deer will select for nutrient-rich habitat while active (foraging, walking) and for secure habitat (cover) while inactive (bedding, ruminating, standing) and that the activity-specific RSFs will thus differ from RSFs developed from data pooled across activity states. We chose to include only females in our study because in deer, the adult female segment disproportionally influences population dynamics (Gaillard et al. 2000) and therefore population management actions primarily target this segment of the population.

\section{STUDY AREA}

We conducted our study on a $1,000-\mathrm{km}^{2}$ section of the Mendocino National Forest, which is located in the interior Coast Range of California, USA, between 2004 and 2013. The study area encompassed 2 major ridges (named M1 and FH7 after the major, unpaved logging roads associated with these ridges) and 3 main watersheds (Fig. 1). Elevation in the study area ranged from $158 \mathrm{~m}$ to $2,462 \mathrm{~m}$ above sea level. The topography varied from moderately rolling terrain at lower elevations to steep and rugged terrain at higher elevations except on ridge tops. Mean daily temperatures ranged from $5^{\circ} \mathrm{C}$ during winter months (Dec-Mar) to $17^{\circ} \mathrm{C}$ during summer months (Jun-Sep; Mendocino Pass weather station; http://www.ncdc.noaa.gov/cdo-web, accessed 09 Sep 2014).
However, temperatures reached extremes of below $-10^{\circ} \mathrm{C}$ and above $40^{\circ} \mathrm{C}$ in winter and summer, respectively. Precipitation over the study period averaged $148.8 \mathrm{~cm} /$ year and was seasonal, with about $85 \%$ of the precipitation occurring from October through April. Snow cover was generally limited to elevations $>1,000 \mathrm{~m}$ and was irregular, particularly during dry winters.

Vegetation in the study area varied with elevation and aspect. Oak woodlands (dominated by oaks [Quercus spp.], California buckeye [Aesculus californica] and manzanita [Arctostaphylos spp.]), chaparral (dominated by buckbrush [Ceanothus spp.] and chamise [Adenostoma fasciculatum]), and grasslands (dominated by brome [Bromus spp.] and wild oat [Avena spp.]) were common at lower elevations and southerly slopes. Mixed-coniferous hardwood forests consisting of ponderosa pine (Pinus ponderosa), sugar pine (Pinus lambertiana), white fir (Abies concolor), red fir (Abies magnifica), Douglas fir (Pseudotsuga menziesii), Pacific madrone (Arbutus menziesii), and oaks dominated higher elevations and northerly slopes. Silviculture and cattle grazing were the primary land management activities in the past and left a mosaic of even-aged conifers with occasional mature timber stands and openings dominated by non-native grasses.

Black-tailed deer were the only resident and abundant ungulate in the study area. Other ungulates present in the study area included feral wild pigs (Sus scrofa) at lower elevations and seasonally abundant domestic cattle. Tule elk (C. c. nannodes), observed twice during the study period, were likely dispersing individuals from a population reintroduced to the extreme southern end of the study area. Pumas (Puma concolor) were the primary predator of adult female deer; fawns were also killed by American black bears (Ursus americanus), coyotes (Canis latrans), and bobcats (Lynx rufus; Marescot et al. 2015).

\section{METHODS}

\section{Capture and Monitoring}

We captured female black-tailed deer $\geq 1$-year-old between September 2004 and August 2013. Captures primarily occurred during summer at high elevations. We did not capture or monitor deer between September 2008 and June 2009. We captured deer opportunistically while driving along unpaved logging roads using chemical immobilization via free range darting. Detailed capture and handling procedures are described in Casady and Allen (2013). All procedures were approved by the Wildlife Investigations Laboratory of the California Department of Fish and Wildlife and the Institutional Animal Care and Use Committee at the University of California, Davis (protocols 15341 and 16886).

We fitted anaesthetized deer with numbered ear tags and motion-sensitive, store-on-board global positioning system (GPS)-collars (Telonics, Mesa, AZ, USA and models 3300 and 4400M, Lotek Wireless, Newmarket, Ontario, Canada). We programmed collars to obtain a GPS location every 1-7 hours (number of fixes/collar $=2,634.4 \pm 301.1$ [SE]). 


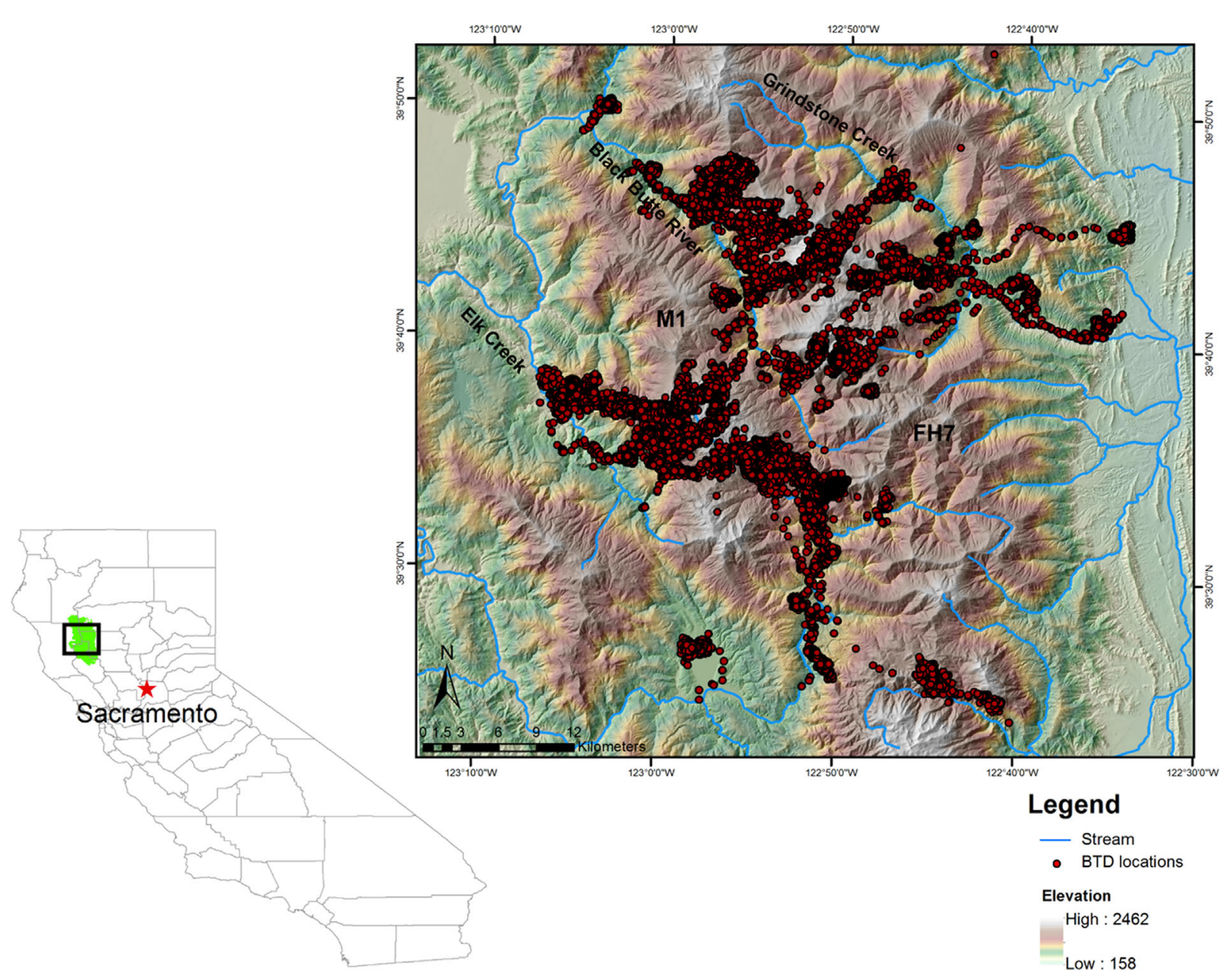

Figure 1. Study area in the Mendocino National Forest, California, USA, including 2 main ridges (M1 and FH7) and 3 main watersheds. We present fixes from all 64 global positioning system (GPS)-collared adult female black-tailed deer (BTD) monitored in the study area, $2004-2013$.

Collars were deployed on deer for a maximum of 2 years, after which they dropped off. All collars were programmed to emit very high frequency (VHF) mortality signals after 4 hours of inactivity, facilitating collar recovery and identification of mortality causes (Marescot et al. 2015).

\section{Home-Range Estimation and Activity States}

We assigned GPS locations of individual deer to summer, winter, or migration seasons based on observed patterns in elevational movements and space use. Based on the seasonal locations, we subsequently determined high elevation summer and low elevation winter home ranges of migratory deer separately using fixed-kernel density estimates (kde) as a metric to estimate the area of utilization distribution for each individual (Seaman and Powell 1996) using the package adehabitat (Calenge 2006) in program $\mathrm{R}$ ( $\mathrm{R}$ Development Core Team 2014). We then used the ad hoc smoothing parameter $\left(\mathrm{h}_{\text {ad hoc }}\right)$ and determined home range boundaries based on 95\% isopleths (Seaman and Powell 1996). For deer that did not migrate between distinct seasonal ranges, we determined $95 \%$ kde based on all acquired locations for each individual and created annual home ranges.

We assigned either inactive or active states to the GPS locations of individuals fitted with Lotek 4400M collars equipped with activity sensors. Activity sensors are made of 2 accelerometers that record changes in acceleration associated with animal motion along the $x$ and $y$ axes of the body 4 times per second. We averaged motion data from each accelerometer over the duration of 5 minutes, which resulted in assignment of a single activity monitor value (AMV) ranging from 0 to 255 for each axis (Gaylord et al. 2016). We log transformed the $x$ and $y$ AMVs and classified them based on discriminant function models developed by Gaylord (2013) for classifying activity states of deer collared with the same collar model (i.e., Lotek 4400M). Model performance had been tested by Gaylord (2013) by linking behavioral observations of captive deer with activity data collected by their collars. We assigned activity states to GPS locations based on average values for the 5-minute interval that overlapped the time a GPS location was taken. We chose to use a 2-state model that differentiated between inactive (bedding, bedding and ruminating, standing, standing and ruminating) and active (foraging, walking, running) only because initial models considering 3 activity states (e.g., differentiating among inactive, foraging or walking, and running behaviors) reduced the number of locations we could assign behaviors to from $82 \%$ to $76 \%$, respectively (Gaylord 2013). The majority of locations we classified as active were 
associated with foraging and walking behaviors; only $1.6 \%$ of locations were classified as running behaviors in the initial 3state model.

\section{Habitat Covariates}

For our RSF analyses we included covariates that influence patterns of habitat selection and habitat use by female blacktailed deer (Bunnell 1990, Gillingham 2004). We obtained 30$\mathrm{m} \times 30-\mathrm{m}$ resolution raster data layers for the study area and prepared a suite of geographic information system (GIS) layers of selected variables for the analyses (Table 1). We obtained elevation data from the Advanced Spaceborne Thermal Emission and Reflection radiometer (ASTER) global digital elevation model (GDEM; https://earthexplorer.usgs.gov, accessed 06 Feb 2015). We derived topographic variables including slope (\%) and aspect (sine and cosine transformed to remove circularity) from the ASTER GDEM layer using Spatial Analyst surface tools in ArcGIS 10.2 (Environmental System Research Institute [ESRI], Redlands, CA, USA). We derived vector ruggedness measures (VRM) from ASTER GDEM in ArcGIS following Sappington et al. (2007).

We acquired vegetation layers including type, succession class (i.e., stand age), canopy cover and height, and canopy at base height (i.e., vertical cover) from Landscape Fire and Resource Management Planning databases (LandFire; www. landfire.gov, accessed $20 \mathrm{Feb} 2015$ ) for the study area (Table 1). Based on proposed ecological importance for black-tailed deer (e.g., Dasmann and Taber 1956, Wallmo 1981), we re-classified vegetation into 7 distinct habitat categories: oak forest, oak shrub, conifer, grassland, riparian, non-oak shrub, and other (water, barren, developed upland forests, and agricultural land). We used conifer as the reference class for comparison among vegetation types because it was the most abundant form of vegetation in summer and winter ranges.

Stand age is an important ecological covariate for most ungulates, including black-tailed deer, because younger forest stands generally provide opportunities for foraging, whereas older forest stands facilitate thermoregulation (Bunnell 1990). Therefore, we classified forest stands by age and successional classes as following: regenerative or very young (0-19 yr), young (20-39 yr), intermediate (40-79 yr), mature (80-120 $\mathrm{yr})$, and old $(>120 \mathrm{yr})$. A sixth class contained all other vegetation types (uncharacteristic native, exotic, barren, water). We also used edge density as a predictor variable in our analyses. We defined edge as the interface between open (herbaceous vegetation, shrubs, grasslands independent of age, and regenerating forests $<20$ years old) and closed-canopy (all forest successional classes $\geq 20$ years) vegetation and between river, stream, or road edges and any adjacent vegetation type. We calculated the density of these linear features per pixel using Spatial Analyst density tools in ArcGIS 10.2.

\section{Statistical Analyses}

We implemented a use-availability design (Manly et al. 2002) to evaluate the influence of environmental variables on habitat selection by female black-tailed deer across seasons and activity states. We estimated resource availability by drawing 1,000 random points from within each individuals' winter and summer home ranges. We used the same set of random locations from within seasonal home ranges for the pooled and activity-specific RSFs.

We estimated RSFs using logistic regression of the form

$$
g(\mathrm{x})=\ln \left[\frac{\pi(X)}{1-\pi(x)}\right]=\beta_{0}+\beta_{1} x_{1 i j}+\ldots+\beta_{n} x_{n i j}+\gamma_{0 j},
$$

Table 1. Habitat covariates used in models to estimate habitat selection by 64 female black-tailed deer in the Mendocino National Forest, California, USA, 2004-2013.

\begin{tabular}{|c|c|c|c|}
\hline Variables & Description & Source & $\begin{array}{l}\text { Variable } \\
\text { type }\end{array}$ \\
\hline \multicolumn{4}{|l|}{ Topography } \\
\hline Elevation $(\mathrm{m})$ & Elevation above sea level & $\begin{array}{l}\text { Global digital elevation (DEM) model (https:// } \\
\text { earthexplorer.usgs.gov/) }\end{array}$ & Continuous \\
\hline Slope (\%) & Slope gradient & Derived from DEM following Horn (1981) & Continuous \\
\hline Cos aspect & Cosine-transformed aspect (northness) & Derived from DEM following Horn (1981) & Continuous \\
\hline Sine aspect & Sine-transformed aspect (eastness) & Derived from DEM following Horn (1981) & Continuous \\
\hline VRM & Vector ruggedness measure & $\begin{array}{l}\text { Derived from DEM following Sappington et al. } \\
(2007)\end{array}$ & Continuous \\
\hline \multicolumn{4}{|c|}{ 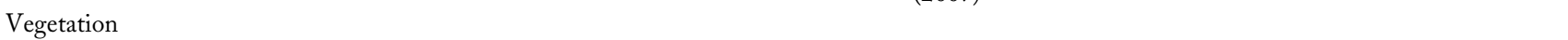 } \\
\hline Type & Complexes of plant communities & http://www.landfire.gov/ & Categorical \\
\hline Succession class & $\begin{array}{l}\text { Current vegetation conditions with respect to } \\
\text { species composition, cover, and height } \\
\text { ranges of successional states within each biophysical } \\
\text { setting }\end{array}$ & http://www.landfire.gov/ & Categorical \\
\hline Cover $(\%)$ & $\begin{array}{l}\text { Proportion of the forest floor covered by the vertical } \\
\text { projection of the tree crowns }\end{array}$ & http://www.landfire.gov/ & Continuous \\
\hline $\begin{array}{l}\text { Canopy height } \\
(\mathrm{m})\end{array}$ & Average height of the top of the canopy & http://www.landfire.gov/ & Continuous \\
\hline $\begin{array}{l}\text { Canopy at base } \\
\text { height }(\mathrm{m})\end{array}$ & $\begin{array}{l}\text { Average height from ground to a forest stand's canopy } \\
\text { bottom }\end{array}$ & http://www.landfire.gov/ & Continuous \\
\hline $\begin{array}{l}\text { Edge density } \\
\left(\mathrm{m} / \mathrm{m}^{2}\right)\end{array}$ & The total length of linear features per pixel & $\begin{array}{l}\text { Derived combining vegetation type, stream, } \\
\text { and track layers }\end{array}$ & Continuous \\
\hline
\end{tabular}


where $\beta_{n}$ is the estimated coefficient for covariate $x_{n}$, and $\gamma_{0 j}$ is the random per-subject intercept (Gillies et al. 2006). This method effectively controls for variation due to unbalanced individual sampling (Gillies et al. 2006, Hebblewhite and Merrill 2008).

To evaluate how pooled RSFs (across activity states) compare with activity-specific RSFs (active and inactive), we built a set of 10 a priori candidate models (Table 2) with a combination of topographic variables and vegetation layers known to affect black-tailed deer habitat selection. We then evaluated performance of these 10 candidate models for each of the following 9 periods or scenarios: summer pooled, summer active, summer inactive, winter pooled, winter active, winter inactive, non-migratory pooled, non-migratory active, nonmigratory inactive. We tested for multicollinearity among the predictor variables used in each model and did not include variables with variance inflation factor (VIF) $\geq 3$ together in any model (Zuur et al. 2010). Because canopy height and canopy cover were correlated, we retained canopy cover and canopy at base height in our cover model as proxy for thermal and security cover. To allow direct comparisons of parameter estimates, we scaled all continuous variables by subtracting the mean and dividing by the standard deviation of the input variable. We fit generalized linear mixed models (GLMMs) using the library lme4 (Bates et al. 2007) in Program R (R Development Core Team 2014). We used an informationtheoretic approach based on Akaike's Information Criterion (AIC) to evaluate model performance and considered models with $\triangle$ AIC $\leq 7$ to contain biological relevant information (Burnham and Anderson 2002).

We assessed model fit using a $k$-fold cross-validation method (Boyce et al. 2002, Long et al. 2009b). We randomly partitioned the data by individual within seasonal models to construct a training set ( $80 \%$ of data) and test set $(20 \%$ of data). We then used model-averaged estimates from our training models to calculate predicted RSF values for the random locations. Subsequently, we ranked the random locations based on predicted values and binned them into 10 equal groups (Boyce et al. 2002). We then quantified the fit using the Spearman rank correlation coefficient based on the frequency of used points in each of 10 equal bins of predicted values (Boyce et al. 2002).

\section{RESULTS}

Of the 84 female deer we captured, 3 died from capturerelated injuries and the collars of 4 individuals failed immediately. The GPS location data from an additional 13 individuals could not be retrieved because of collar malfunction. For the remaining 64 individuals, we collected 168,599 GPS locations. Twenty-seven of these 64 individuals had activity data recorded (Table 3 ) and we collected 57,581 fixes from these 27 individuals. Based on the accelerometer data, $10 \%$ of fixes were classified as active and $90 \%$ as inactive (Table 3). We excluded 5,658 locations associated with elevational migrations from RSF models. Fix success rates averaged $83.81 \pm 1.4 \%$ [SE] for all 64 individuals and $83.46 \pm 1.56 \%$ for the 27 individuals with activity collars.

\section{Habitat Selection Pooled Models}

Results excluding state information showed support for a single best model $(\Delta \mathrm{AIC}>2)$ for each of the 9 scenarios explaining habitat selection of black-tailed deer at the home range scale, but the best model differed for migratory and non-migratory individuals (Table 4; Table S1, available online in Supporting Information). In general, migratory black-tailed deer selected for more secure habitats, whereas non-migratory black-tailed deer selected for more productive habitats year around. Selection for specific variables, however, changed over the course of the year and depended on migratory status (Table 5).

Migratory black-tailed deer selected for higher elevations $(\beta=0.23)$, gentler slopes $(\beta=-0.05)$, and east- and southeast-facing aspects $(\cos \beta=-0.10$; $\sin \beta=0.08)$ in summer. They also selected areas with lower edge density ( $\beta=-0.68)$, lower canopy cover $(\beta=-0.21)$, and higher proportion of oak forests $(\beta=0.26)$ and avoided old forest stands ( $\beta=-0.35 ;$ Fig. 2$)$. In winter, migratory black-tailed deer mostly selected for lower elevations $(\beta=-0.26)$, steeper slopes $(\beta=0.06)$, and north- and east-facing aspects (cos $\beta=0.20 ; \sin \beta=0.03)$. They also selected higher edge density $(\beta=0.44)$, old oak forest stands $(\beta=0.17$; Fig. 2$)$, and open vegetation including shrubs $(\beta=0.09)$ and grassland $(\beta=0.29)$.

Table 2. Candidate models and number of parameters $(K)$ used to determine habitat selection by 64 female black-tailed deer in the Mendocino National Forest, California, USA, 2004-2013. Models based on pooled and activity-specific global positioning system locations at the home range scale.

\begin{tabular}{llr}
\hline Model name & & \multicolumn{1}{c}{ Model covariates } \\
\hline Null & Null & 2 \\
Physical & Elevation $+\cos ($ aspect $)+\sin ($ aspect $)+$ slope + ruggedness & 7 \\
Vegetation 1 & Edge density + canopy cover + canopy at base height + vegetation type $\times$ S-class $1{ }^{\text {a }}$ & 17 \\
Vegetation 2 & Edge density + canopy cover + canopy at base height + vegetation type $\times$ S-class 2 & 17 \\
Vegetation 3 & Edge density + canopy cover + canopy at base height + vegetation type $\times$ S-class 3 & 17 \\
Vegetation 4 & Edge density + canopy cover + canopy at base height + vegetation type $\times$ S-class 4 & 16 \\
Vegetation 5 & Edge density + canopy cover + canopy at base height + vegetation type $\times$ S-class 5 & 13 \\
Food 1 & Elevation $+\cos ($ aspect $)+\sin ($ aspect $)+$ slope + ruggedness + edge density + vegetation type $\times$ S-class 1 & 20 \\
Food 2 & Elevation $+\cos ($ aspect $)+\sin ($ aspect $)+$ slope + ruggedness + edge density + vegetation type $\times$ S-class 2 & 20 \\
Cover & Elevation $+\cos ($ aspect $)+\sin ($ aspect $)+$ slope + edge density + canopy cover + canopy at base height + vegetation type $\times$ S-class 5 & 17 \\
\hline
\end{tabular}

${ }^{a}$ Succession classes: S-class $1=$ regenerative or very young $(0-19 \mathrm{yr})$, S-class $2=$ young $(20-39 \mathrm{yr})$, S-class $3=$ intermediate $(40-79 \mathrm{yr})$, S-class $4=$ mature (80-120 yr), S-class $5=$ old $(>120 \mathrm{yr})$. 
Table 3. Total number of female deer $\left(\mathrm{n}_{\mathrm{D}}\right)$, number of deer with activity data $\left(\mathrm{n}_{\mathrm{A}}\right)$, and number of global positioning system (GPS) locations used in models to estimate habitat selection by 64 female black-tailed deer in the Mendocino National Forest, California, USA, 2004-2013.

\begin{tabular}{lcccc}
\hline & & \multicolumn{3}{c}{ Number of GPS locations } \\
\cline { 3 - 5 } Season & $\mathbf{n}_{\mathbf{D}}\left(\mathbf{n}_{\mathbf{A}}\right)$ & Pooled & Active & Inactive \\
\hline Migratory summer & $51(22)$ & 79,110 & 2,439 & 23,603 \\
Migratory winter & $45(20)$ & 63,132 & 2,370 & 21,945 \\
Non-migratory & $12(5)$ & 20,699 & 778 & 6,446 \\
\hline
\end{tabular}

Non-migratory deer selected for higher elevations $(\beta=0.55)$ with steeper south- and east-facing slopes (cos $\beta=-0.21 ; \sin \beta=0.30$ ) year around. Non-migratory deer also selected grasslands $(\beta=0.61)$ and riparian vegetation $(\beta=0.31)$.

\section{Habitat Selection and Activity States}

Habitat selection by female black-tailed deer varied with activity state (active vs. inactive; Table 5). The selection patterns for habitat covariates including slope, edge density, and vegetation types differed markedly between the statespecific and pooled models (Fig. 3).

In summer, the patterns of selection for land-use and land cover types across activity states mostly differed in strength (i.e., slope of the curve; Table 5; Fig. 3), but the top-ranked model did not vary between activity-specific models (Table 4). When active, migratory black-tailed deer selected areas closer to edges $(\beta=1.08)$ and preferred open vegetation including grasslands $(\beta=0.34)$, shrubs $(\beta=0.48)$, and oak shrubs in young age classes $(\beta=4.09$; Fig. 2$)$. In contrast, migratory black-tailed deer avoided areas with high edge density ( $\beta=-0.99$; Fig. 2). Black-tailed deer selected for open-canopy forests in summer, independent of their activity state (Table 5, Fig. 2).

In winter, top models differed between activity states (Table 4) as patterns of selection changed markedly. When active, migratory black-tailed deer selected for regenerative forest stands $(\beta=0.53$; Fig. 2) with preference for open vegetation including grasslands $(\beta=0.92)$, oak shrubs $(\beta=0.94)$, and shrubs $(\beta=0.65)$. When resting, blacktailed deer selected for vegetation and cover types providing thermal cover and showed significant preference for old forests stands ( $\beta=1.58$; Fig. 2$)$ and dense canopy cover $(\beta=0.54)$. In addition to choosing dense canopy forest, individuals also selected for areas with vertical cover $(\beta=-0.38)$. Female black-tailed deer switched from selecting gentle slopes $(\beta=-0.42)$ when active to steeper slopes $(\beta=0.03)$ when inactive. Parameter estimates for edge density across both states showed a consistent preference for areas with higher edge density in winter (Fig 3; Table 5).

The top-ranked model remained consistent across activity states for non-migratory black-tailed deer (Table 4). Nonmigratory black-tailed deer selected for habitat with oak

Table 4. Habitat selection model results for migratory and non-migratory female black-tailed deer in the Mendocino National Forest, California, USA, 20042013. Results show best ( $\triangle$ AIC $\leq 7)$ models based on pooled locations and differentiating between 2 activity states (active and inactive). Selection for migratory deer is further delineated for 2 distinct seasons (summer and winter) based on observed elevational migrations.

\begin{tabular}{|c|c|c|c|c|}
\hline Model & $K^{\mathrm{a}}$ & $\mathrm{AIC}^{\mathrm{b}}$ & $w_{i}^{\mathbf{c}}$ & $r_{\mathrm{s}}^{\mathrm{d}}$ \\
\hline \multicolumn{5}{|l|}{ Summer pooled } \\
\hline $\begin{array}{l}\text { Elevation }+\cos (\text { aspect })+\sin (\text { aspect })+\text { slope }+ \text { edge density }+ \text { canopy cover }+ \text { canopy at base height }+ \text { vegetation } \\
\text { type } \times \text { S-class } 5^{\mathrm{e}}\end{array}$ & 17 & $139,860.90$ & 1.00 & 0.79 \\
\hline \multicolumn{5}{|l|}{ ( } \\
\hline $\begin{array}{l}\text { Elevation }+\cos (\text { aspect })+\sin (\text { aspect })+\text { slope }+ \text { edge density }+ \text { canopy cover }+ \text { canopy at base height }+ \text { vegetation } \\
\text { type } \times \text { S-class } 5\end{array}$ & 17 & $12,799.71$ & 0.93 & 0.65 \\
\hline Elevation $+\cos ($ aspect $)+\sin ($ aspect $)+$ slope + ruggedness + edge density + vegetation type $\times$ S-class 2 & 20 & $12,804.95$ & 0.07 & 0.72 \\
\hline \multicolumn{5}{|l|}{ Summer inactive } \\
\hline $\begin{array}{l}\text { Elevation }+\cos (\text { aspect })+\sin (\text { aspect })+\text { slope }+ \text { edge density }+ \text { canopy cover }+ \text { canopy at base height }+ \text { vegetation } \\
\text { type } \times \text { S-class } 5\end{array}$ & 17 & $49,791.82$ & 1.00 & 0.77 \\
\hline \multicolumn{5}{|l|}{ Winter pooled } \\
\hline $\begin{array}{l}\text { Elevation }+\cos (\text { aspect })+\sin (\text { aspect })+\text { slope }+ \text { edge density }+ \text { canopy cover }+ \text { canopy at base height }+ \text { vegetation } \\
\text { type } \times \text { S-class } 5\end{array}$ & 17 & $12,0481.20$ & 1.00 & 0.81 \\
\hline \multicolumn{5}{|l|}{ Winter active } \\
\hline Elevation $+\cos ($ aspect $)+\sin ($ aspect $)+$ slope + ruggedness + edge density + vegetation type $\times$ S-class 1 & 20 & $12,110.25$ & 1.00 & 0.75 \\
\hline \multicolumn{5}{|l|}{ Winter inactive } \\
\hline $\begin{array}{l}\text { Elevation }+\cos (\text { aspect })+\sin (\text { aspect })+\text { slope }+ \text { edge density }+ \text { canopy cover }+ \text { canopy at base height }+ \text { vegetation } \\
\text { type } \times \text { S-class } 5\end{array}$ & 17 & $42,228.38$ & 1.00 & 0.80 \\
\hline \multicolumn{5}{|l|}{ Non-migratory pooled } \\
\hline Elevation $+\cos ($ aspect $)+\sin ($ aspect $)+$ slope + ruggedness + edge density + vegetation type $\times$ S-class 1 & 20 & $38,565.93$ & 1.00 & 0.83 \\
\hline \multicolumn{5}{|l|}{ Non-migratory active } \\
\hline Elevation $+\cos ($ aspect $)+\sin ($ aspect $)+$ slope + ruggedness + edge density + vegetation type $\times S$-class 1 & 20 & $2,196.54$ & 0.99 & \\
\hline \multicolumn{5}{|l|}{ Non-migratory inactive } \\
\hline Elevation $+\cos ($ aspect $)+\sin ($ aspect $)+$ slope + ruggedness + edge density + vegetation type $\times S$-class 1 & 20 & $14,507.41$ & 1.00 & \\
\hline
\end{tabular}

${ }^{\mathrm{a}}$ Number of parameters.

b Akaike's Information Criterion.

${ }^{c}$ AIC weight.

d Spearman-rank correlation.

${ }^{\mathrm{e}}$ Succession classes: S-class $1=$ regenerative or very young (0-19 yr), S-class $2=$ young $(20-39 \mathrm{yr})$, S-class $5=$ old $(>120 \mathrm{yr})$. 


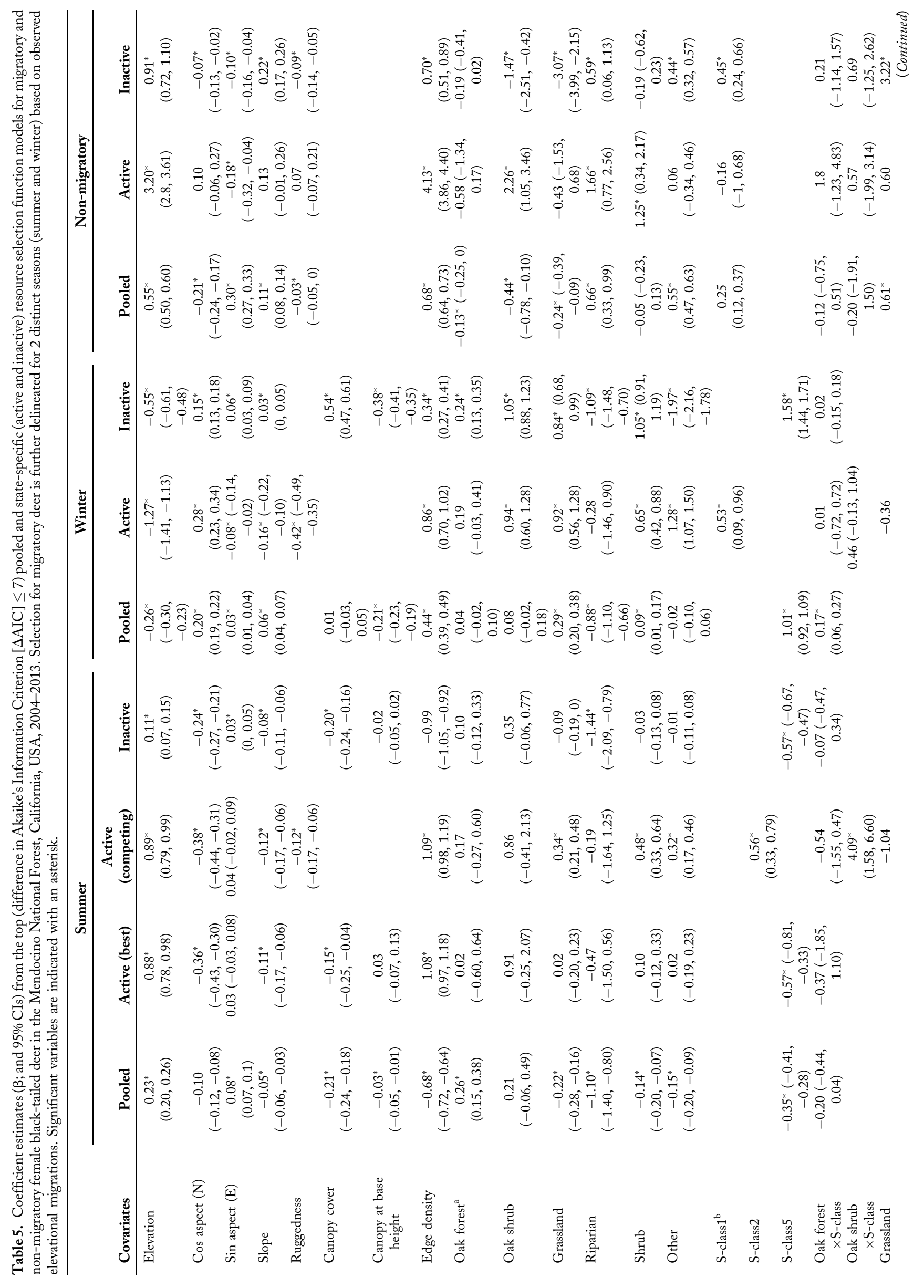




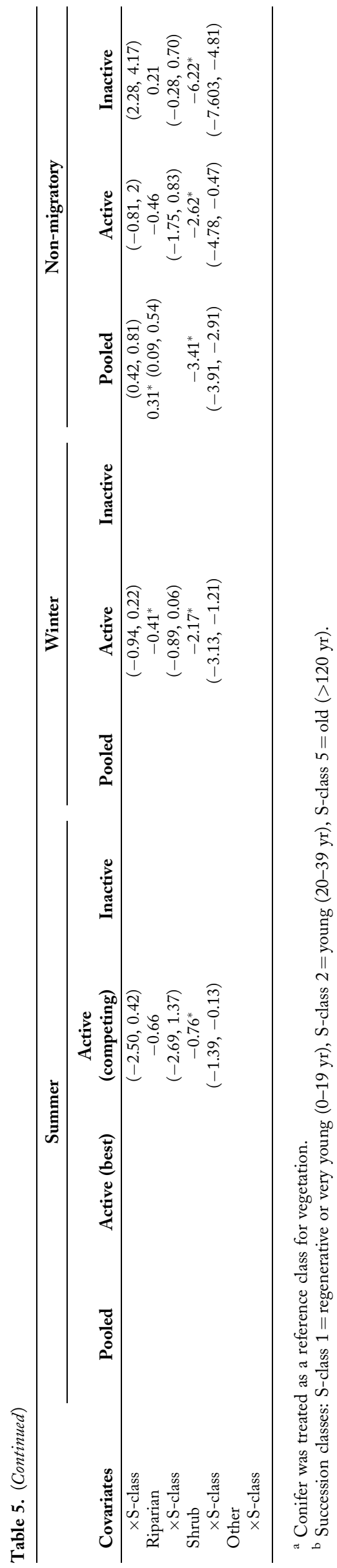

shrub $(\beta=2.26)$, shrub $(\beta=1.66)$, and riparian vegetation ( $\beta=1.66)$ primarily on west-facing slopes $(\beta=-0.18)$ when active. When inactive, non-migratory black-tailed deer showed selection toward steeper $(\beta=0.22)$, southwestfacing ( $\cos \beta=-0.24$; $\sin \beta=0.03$ ) slopes, and grasslands $(\beta=3.22$; Table 5, Fig. 2). They consistently selected areas near edges across both states (Table 5).

The top-ranked resource selection models provided average to good fit to the data using $\mathrm{k}$-fold cross-validation tested with the Spearman rank correlation coefficient $\left(r_{s} \geq 0.65\right.$, $P<0.05$ ) for best models (Table 4). However, we could not test the fit of activity-specific models for the non-migratory deer because of low sample size $(n=5)$.

\section{DISCUSSION}

Our results support the hypotheses that fine-scale habitat selection by black-tailed deer is affected by the variation in selection between activity states (Roever et al. 2014). Comparing models that included information about the activity state of individuals to pooled models influenced conclusions regarding the selection of ecological covariates including edge density, slope, canopy cover, and forest age during summer and winter. These habitat characteristics are central to understanding ungulate biology, and accurately understanding selection of these habitats provided insight into key habitat characteristics that are used for short but critical foraging and walking periods. These results are also likely indicative of fine-scale trade-offs between meeting energetic requirements and spending as little time as possible foraging in habitats with high vulnerability to predation such as edge habitats (Pierce et al. 2004, Allen et al. 2015). Our results offer important insights for optimal foraging theory and the effective management of ungulates in multi-use landscapes.

Topographic variables including elevation, slope, and aspect are primary determinants of broad-scale distribution patterns for black-tailed deer (Bunnell 1990, Bailey et al. 1996). They play a significant role in habitat selection in black-tailed deer, as individuals attempt to balance the energetic costs of foraging and thermal regulation in often rugged terrain (Bunnell 1990). Consistent with previous habitat selection studies (Bunnell 1990, Gillingham 2004), we found black-tailed deer to select for relatively high elevation, and south- and southeast-facing aspects at the home range scale in summer, likely as a consequence of early green-up of forage in these habitats (Xie et al. 2015). In winter, black-tailed deer descended to lower elevations and selected northeastern aspects. Because of the low interspersion of these variables in space, and very small home ranges of our study individuals (Forrester et al. 2015, Bose et al. 2017), the pattern of selection remained consistent across activity states. Selection patterns for slope in black-tailed deer, however, showed opposing patterns across activity states that affected the outcome of the pooled models. The pooled winter model detected positive selection of individuals toward steeper slopes, which contradicts with predictions based on optimal foraging theory (Krebs 1980, Bergman et al. 2001). Substantially higher energetic costs of 


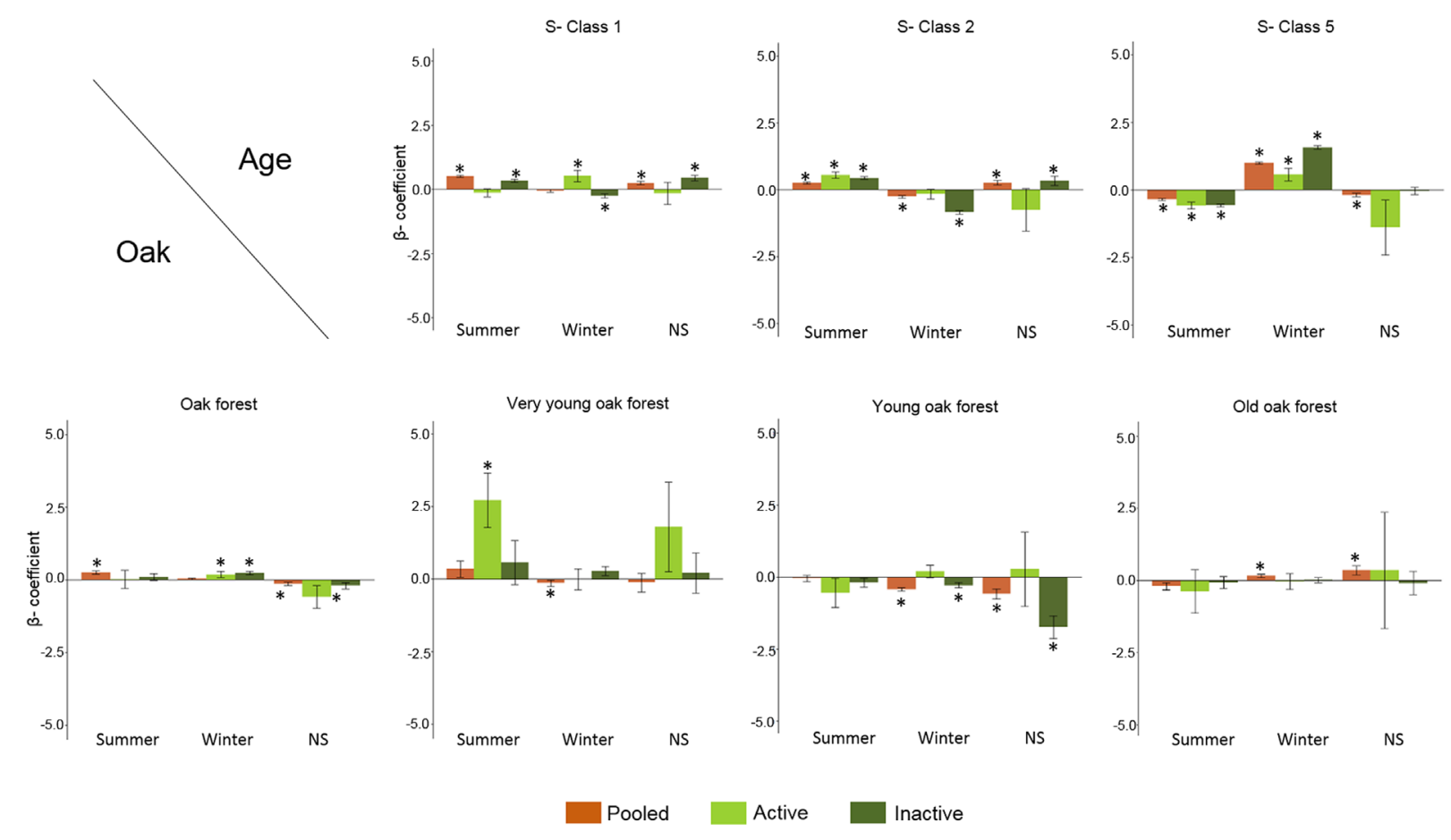

Figure 2. Selection indices for forest age (succession classes S-class $1=$ very young, S-class $2=$ young, and S-class $5=$ mature) and oak forest age and their interactions, based on parameter estimates obtained from resource selection function models for female black-tailed deer in the Mendocino National Forest, California, USA, 2004-2013. We estimated selection indices by season (summer and winter) for migratory deer, pooled locations across years for non-migratory deer (no seasonality or NS), and show how selection differed among pooled and activity-specific models (active and inactive state). Error bars represent $95 \%$ confidence intervals and asterisks show significant parameter estimates.

locomotion would be incurred when traversing steep slopes and consistent use of steeper terrain within their home ranges could significantly increase the energy expended on movement during each foraging bout (Parker et al. 1984). When we considered selection based on active and inactive states, individuals only selected for steeper slopes during inactive states while resting, likely as an effective antipredator strategy (Riley and Dood 1984, Apps et al. 2013). During active states individuals selected for gentler slopes, consistent with optimal foraging theory.

Canopy cover is an important determinant for habitat selection in many ungulates and influences vital factors like thermoregulation, concealment, and forage (Bunnell 1990, Mysterud and Østbye 1999). A forest stand with dense canopy can reduce energetic costs of thermoregulation by providing shade but often has reduced quantity of available browse (Lorimer et al. 1994, Frost et al. 1997). Stands with canopy emerging closer to the ground, can provide better quality browse and concealment (Bunnell 1990, Camp et al. 2013) but can also conceal predators (Camp et al. 2013). Thus, the selection toward cover exemplifies energetics versus fitness trade-offs (Mysterud and Østbye 1999). As expected because of temporal shift in trade-offs, selection towards vertical and canopy cover varied across seasons and activity states. In summer, female black-tailed deer chose areas with some concealment cover within their home ranges but avoided areas with dense canopy cover across activity states (Fig. 3). In winter, black-tailed deer consistently selected for canopies closer to ground but only selected for dense canopy cover when inactive. We hypothesize that because of higher predation risks during summer in our study area (Allen et al. 2014) black-tailed deer preferred higher elevations without dense, concealing vegetation because it provided visual advantage over predators (Smith et al. 1986) while foraging and resting. Conversely, during winter, when pumas in the study area suffered less kleptoparasitism from black bears (Elbroch et al. 2015), kill rates of black-tailed deer were lower (Allen et al. 2014), and need for quality forage and thermal cover outweighed predation risk. Hence, deer in the study area chose forest stands with canopy cover closer to the ground, which provide them with sufficient forage and security cover when active (Bunnell 1990, Mysterud and Østbye 1999). Additionally, as black-tailed deer spend longer periods resting and ruminating during winter to digest forage with higher lignin content (Bunnell 1990), moving to a covered habitat is an efficient way of thermoregulation (Mysterud and Østbye 1999).

Black-tailed deer select edge habitats (Chang et al. 1995, Doerr et al. 2005) because individuals can use relatively high quality forage in these habitats, while being close to protective cover (Leopold 1933). However, in our pooled summer model we observed clear avoidance toward edge density unlike some previous studies (Hanley 1983, Kremsater and Bunnell 1992, Kie et al. 2002). The result was particularly notable because avoidance toward open vegetation like grasslands and shrubs away from the edges implies selection of areas away from preferred forage in summer habitat (Bunnell 1990). We expected activity state to influence these results and, indeed, found that during active states, black-tailed deer showed significant positive selection 

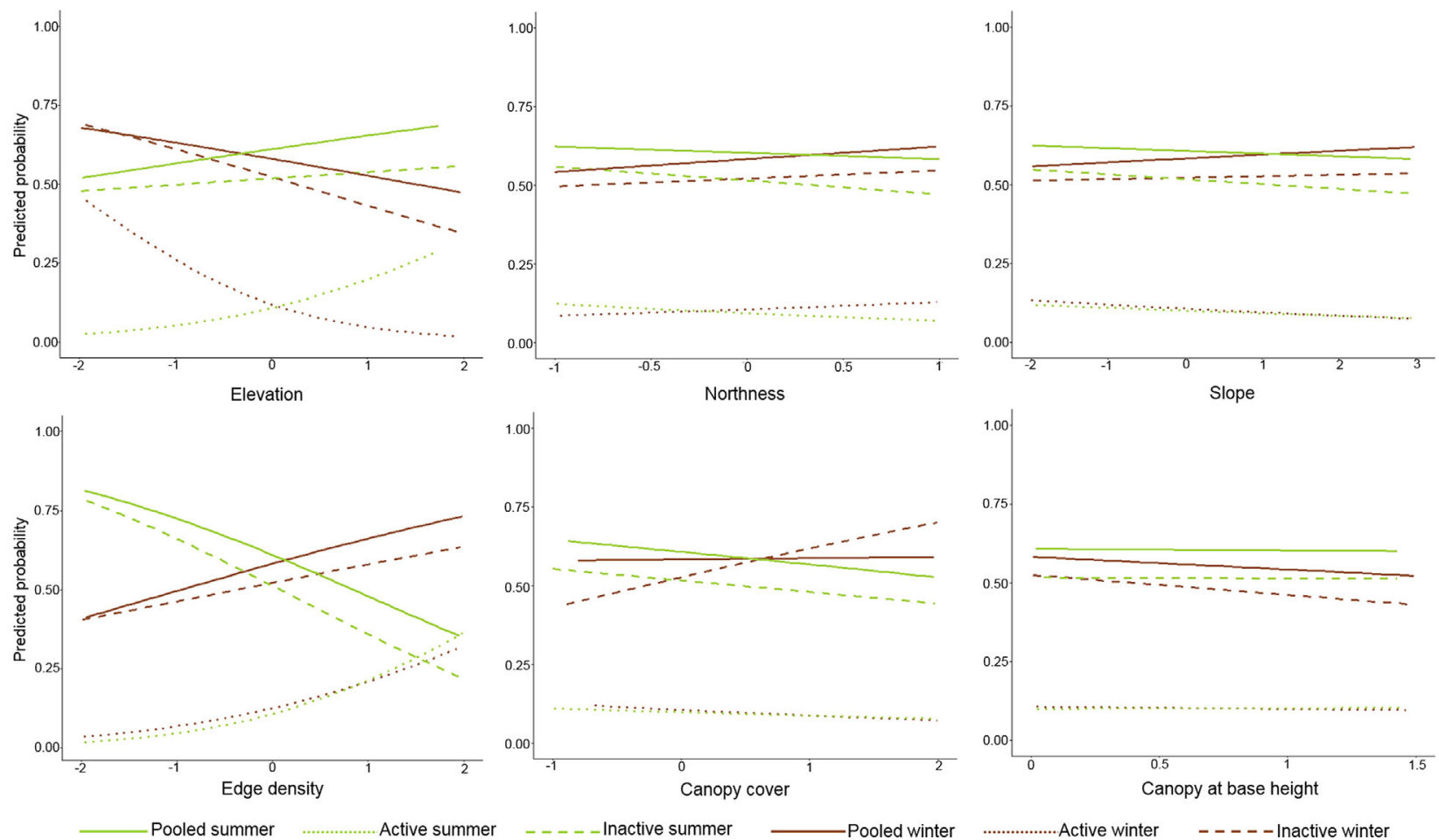

Figure 3. Predicted probability of selection for elevation, aspect (northness), slope, edge density, canopy cover, and canopy at base height as a function of seasons (summer and winter) and activity states (locations pooled across activity states, active, and inactive) by female black-tailed deer in the Mendocino National Forest, California, USA, collared between 2004 and 2013. For canopy at base height, negative slope of selection indicates selection for hiding cover or canopy cover closer to the ground.

toward high edge density, whereas we observed significant avoidance during inactive states. Black-tailed deer need to access high quality forage associated with edge habitats to meet high energetic demands associated with fawning (Parker et al. 2009) but in doing so face higher predation risks (Allen et al. 2015). To rest and ruminate, black-tailed deer moved away from edge habitat into safer areas in more homogenously vegetated areas on steeper slopes likely because of improved ability to detect approaching predators (Creel et al. 2005).

Previous studies on ungulates have reported the importance of quality and quantity of forage on reproduction (Taillon et al. 2006), growth (Fryxell 1991), and survival (Forrester et al. 2015). Black-tailed deer (and other ungulates) at higher latitudes generally prefer herbaceous vegetation and other high energy forage when available because of their higher energy content (Bunnell and Gillingham 1985, Cook et al. 2016). Because nutrient content and digestibility of the plant parts varies with season (Mauffette and Oechel 1989, Salminen et al. 2004) and age (van Soest 1994), we tried to determine if the activity state of black-tailed deer affected selection of the age classes of particular vegetation types. In summer, deer selected nutrient rich, young oak shrubs, and oak forest during active states, consistent with previous studies (Dasmann and Taber 1956, Forrester et al. 2015). However, black-tailed deer selected for old coniferous forest when inactive possibly as shade from higher ambient temperatures (van Beest et al. 2012). In winter, we suspect female black-tailed deer preferred younger oak shrubs and coniferous forest to get maximum nutrition from their forage, and chose mature coniferous forest with understory growth during inactive state for better thermal and security cover (Bowyer and Kie 2009). As expected, the pooled models failed to identify the variation in selection toward age-specific vegetation types with changing activity states (Fig. 2). The misidentification and non-detection of blacktailed deer selection of specific vegetation types and age classes is of particular concern in managed landscapes such as national forests, where large-scale habitat conversion (e.g., timber harvest and livestock grazing) may result in homogenous habitats. Homogeneous habitat will likely not meet all requirements for individual black-tailed deer, thus prompting individuals to venture out of their familiar home ranges and increase the risk of mortality (Forrester et al. 2015).

Like other ungulates, black-tailed deer likely use habitats differently at various stages of their life to meet resource requirements associated with growth, reproduction, and survival (Kie and Bowyer 1999). We were unable to test for differences in habitat selection among individuals of different age and physiological requirements, which may partly explain the limited predictability of our habitat selection models. For example, although pregnancy rates were consistently high in our study, fawn survival over the first 3 months following birth was low and variable (Marescot et al. 2015). It is likely that resource requirements of females losing their fawns early in summer was different from females with surviving offspring. Without detailed data on changes in reproductive 
status of females in summer, however, we were unable to evaluate how differences in energetic requirements associated with raising a fawn affected habitat selection. Although females with higher resource needs may have shown stronger selection of habitats with high quality forage, it unlikely influenced our conclusions regarding habitat use from resource selection models based on pooled data versus those differentiating between activity states.

Our results support findings from a small but rapidly growing body of literature (Ager et al. 2003, Godvik et al. 2009, Roever et al. 2014) that highlight the importance of considering activity states and behavior when determining habitat selection. As observed by Roever et al. (2014), we found the assessment of the importance of habitat covariates based on strength of selection from the pooled model to be inaccurate and sometimes misleading. We also observed opposing selection patterns between activity states for parameters that are highly interspersed in space. This frequently led to misidentification of selection patterns for important ecological covariates in the pooled model. We suggest that this may have arisen from the high-frequency feeding-resting-feeding cycles of ruminants, such as blacktailed deer, leading to pronounced differences in selection patterns across different activity states in a very short period of time. Small-bodied ungulates have evolved strategies to minimize foraging time (rumination, selecting high quality forage), and it is important to use selection models that measure selection for all activity states to accurately test prediction of foraging and energetic theory.

Although using GPS collars fitted with dual-axis acceleration sensors have clear advantages, challenges regarding misclassification of activity states remain. For example, results from previous studies reveal that misclassification of activity data can be affected by factors including terrain, age, sex, and season (Löttker et al. 2009, Gaylord et al. 2016). The fit of the collar around the neck also influences how easily acceleration sensors are triggered by movements (Coulombe et al. 2006, Brooks et al. 2008) because a tighter collar fit around the neck may trigger sensors more easily, thus increasing the number of locations an individual is considered active. In our study, the number of locations where black-tailed deer were considered active was approximately 3.4 times lower than expected based on previous research in winter (Kuhfeld et al. 1988). Although collar fit may have contributed to the lower number of locations associated with activity, other factors likely did as well. Specifically, 8 of our collars were programmed to collect activity data every 1 minute as opposed to the 5 -minute time interval recommended by Gaylord et al. (2016). Despite retrospectively adjusting data for these collars to 5-minute intervals, only $6.35 \pm 1.03 \%$ of locations retrieved from these 8 collars were classified as active. Activity estimates from collars programmed to collect activity data averaged across 5 minutes were significantly higher $(14.29 \pm 3.27 \%)$. The low number of active locations was likely also affected by our decision to excluded locations associated with migrations between summer and winter ranges from the habitat selection analysis. Combined, our results are thus based on a conservative assessment of activity (i.e., a low probability that an inactive state was misclassified as active). However, we also believe that several conditions pertinent to our study area support the low number of locations associated with an active state. For example, home ranges of black-tailed deer in our study were extremely small $\left(0.71 \mathrm{~km}^{2}\right.$ in summer, $0.99 \mathrm{~km}^{2}$ in winter; Bose et al. 2017) resulting in very short travel distances between habitats used for foraging versus resting. In addition, our study area supports among the highest densities of black-tailed deer recorded across their range (Lounsberry et al. 2015), indicating high habitat productivity and likely shorter foraging and walking bouts. Thus despite some limitation, our results highlight advantages examining differences in habitat selection and activity state.

\section{MANAGEMENT IMPLICATIONS}

Our results infer that habitat enhancement for black-tailed deer, which is predominately achieved via activities that promote high-energy new plant growth, should be concentrated on foraging areas. Oppositely, disturbance to mature forest stands, especially on slopes, with pronounced edges adjacent to foraging areas should be avoided to maintain both thermal and escape cover. The resulting fine-scale mosaic of habitat types is likely best suited for sustaining black-tailed deer populations in multi-predator systems. Habitat enhancement at fine scales is particularly important given the high site fidelity and philopatry reported for the species (Bose et al. 2017). Traditional large-scale homogenous habitat enhancements are unlikely to meet needs associated with different behavioral states and thus sustain healthy deer populations. Our results also suggest that habitat enhancement may have to target different habitat types to be effective for non-migratory deer. More generally, our study stresses that for effective deer management and land development planning, resource managers need to be aware of fine-scale habitat requirements for deer and other ungulates, and that these requirements might be masked by analyses using pooled resource selection data. Therefore, it is important for future resource selection studies to include activity data in their analyses so that fine-scale habitat use can be adequately assessed to develop well-informed management plans.

\section{ACKNOWLEDGMENTS}

We thank all students, volunteers, and agency personnel that helped with deer captures and collecting data in the field. J. H. Fischer and 2 anonymous reviewers provided helpful comments on a previous version of the manuscript. The project was funded by the California Department of Fish and Wildlife and the California Deer Association. S. Bose was supported by a Victoria University Doctoral Scholarship and T. D. Forrester by the Robert and Patricia Switzer Foundation.

\section{LITERATURE CITED}

Ager, A. A., B. K. Johnson, J. W. Kern, and J. G. Kie. 2003. Daily and seasonal movements and habitat use by female Rocky Mountain elk and mule deer. Journal of Mammalogy 84:1076-1088. 
Allen, M. L., L. M. Elbroch, D. S. Casady, and H. U. Wittmer. 2014. Seasonal variation in the feeding ecology of pumas (Puma concolor) in northern California. Canadian Journal of Zoology 92:397-403.

Allen, M. L., L. M. Elbroch, D. S. Casady, and H. U. Wittmer. 2015. Feeding and spatial ecology of mountain lions in the Mendocino National Forest, California. California Fish and Game 101:51-65.

Anderson, D. P., J. D. Forester, M. G. Turner, J. L. Frair, E. H. Merrill, D. Fortin, J. S. Mao, and M. S. Boyce. 2005. Factors influencing female sizes in elk (Cervus elaphus) in North American landscapes. Landscape Ecology 20:257-271.

Apps, C. D., B. N. McLellan, T. A. Kinley, and J. P. Flaa. 2001. Scaledependent habitat selection by mountain caribou, Columbia Mountains, British Columbia. Journal of Wildlife Management 65:65-77.

Apps, C. D., B. N. McLellan, T. A. Kinley, R. Serrouya, D. R. Seip, and H. U. Wittmer. 2013. Spatial factors related to mortality and population decline of endangered mountain caribou. Journal of Wildlife Management 77:1409-1419.

Bailey, D. W., J. E. Gross, E. A. Laca, L. R. Rittenhouse, M. B. Coughenour, D. M. Swift, and P. L. Sims. 1996. Mechanisms that result in large herbivore grazing distribution patterns. Journal of Range Management 49:386-400.

Bates, D., D. Sarkar, M. D. Bates, and L. Matrix. 2007. The lme4 package. $\mathrm{R}$ package version 2:74.

Bergman, C. M., J. M. Fryxell, C. C. Gates, and D. Fortin. 2001. Ungulate foraging strategies: energy maximizing or time minimizing? Journal of Animal Ecology 70:289-300.

Bose, S., T. D. Forrester, J. L. Brazeal, B. N. Sacks, D. S. Casady, and H. U. Wittmer 2017. Implications of fidelity and philopatry for the population structure of female black-tailed deer. Behavioral Ecology 28:983-990.

Bowyer, R. T., and J. G. Kie. 2009. Thermal landscapes and resource selection by black-tailed deer: implications for large herbivores. California Fish and Game 95:128-139.

Boyce, M. S., J. S. Mao, E. H. Merrill, D. Fortin, M. G. Turner, J. Fryxell, and P. Turchin. 2003. Scale and heterogeneity in habitat selection by elk in Yellowstone National Park. Ecoscience 10:421-431.

Boyce, M. S., P. R. Vernier, S. E. Nielsen, and F. K. Schmiegelow. 2002. Evaluating resource selection functions. Ecological Modelling 157:281-300.

Brooks, C., C. Bonyongo, and S. Harris. 2008. Effects of global positioning system collar weight on zebra behavior and location error. Journal of Wildlife Management 72:527-534.

Bunnell, F. 1990. Ecology of black-tailed deer. Pages 31-63 in J. B. Nyberg and D. W. Janz, editors. Deer and elk habitat in coastal forests of southern British Columbia Special Report Series. Research Branch British Columbia Ministry of Forests, Victoria, Canada.

Bunnell, F., and M. Gillingham. 1985. Foraging behavior: dynamics of dining out. Pages 53-79 in R. J. Hudson and R. G. White, editors. Bioenergetics of wild herbivores. CRC Press, Boca Raton, Florida, USA.

Burnham, K. P., and D. R. Anderson. 2002. Model selection and multimodel inference: a practical information-theoretic approach. Second edition. Springer-Verlag, New York, New York, USA.

Calenge, C. 2006. The package "adehabitat" for the R software: a tool for the analysis of space and habitat use by animals. Ecological Modelling 197:516-519.

Camp, M., J. Rachlow, B. Woods, T. Johnson, and L. Shipley. 2013. Examining functional components of cover: the relationship between concealment and visibility in shrub-steppe habitat. Ecosphere 4:1-14.

Casady, D. S., and M. L. Allen. 2013. Handling adjustments to reduce chemical capture-related mortality in black-tailed deer. California Fish and Game 99:104-109.

Chang, K.-T., D. L. Verbyla, and J. J. Yeo. 1995. Spatial analysis of habitat selection by Sitka black-tailed deer in southeast Alaska, USA. Environmental Management 19:579-589.

Coulombe, M.-L., A. Massé, and S. D. Côté. 2006. Quantification and accuracy of activity data measured with VHF and GPS telemetry. Wildlife Society Bulletin 34:81-92.

Cook, J. G., R. C. Cook, R. W. Davis, and L. L. Irwin. 2016. Nutritional ecology of elk during summer and autumn in the Pacific Northwest. Wildlife Monographs 195:1-81.
Creel, S., J. Winnie, Jr., B. Maxwell, K. Hamlin, and M. Creel. 2005. Elk alter habitat selection as an antipredator response to wolves. Ecology 86:3387-3397.

D'Eon, R. G., and R. Serrouya. 2005. Mule deer seasonal movements and multiscale resource selection using global positioning system radiotelemetry. Journal of Mammalogy 86:736-744.

Dasmann, R. F., and R. D. Taber. 1956. Behavior of Columbian black-tailed deer with reference to population ecology. Journal of Mammalogy $37: 143-164$

DeCesare, N. J., M. Hebblewhite, M. Bradley, D. Hervieux, L. Neufeld, and M. Musiani. 2014. Linking habitat selection and predation risk to spatial variation in survival. Journal of Animal Ecology 83:343-352.

Doerr, J. G., E. J. Degayner, and G. Ith. 2005. Winter habitat selection by Sitka black-tailed deer. Journal of Wildlife Management 69: 322-331.

Elbroch, L. M., P. E. Lendrum, M. L. Allen, and H. U. Wittmer. 2015. Nowhere to hide: pumas, black bears and competition refuges. Behavioral Ecology 26:247-254.

Forrester, T. D., D. S. Casady, and H. U. Wittmer. 2015. Home sweet home: fitness consequences of site familiarity in female black-tailed deer. Behavioral Ecology and Sociobiology 69:603-612.

Forrester, T. D., and H. U. Wittmer. 2013. A review of the population dynamics of mule deer and black-tailed deer Odocoileus hemionus in North America. Mammal Review 43:292-308.

Frost, W. E., J. W. Bartolome, and J. M. Connor. 1997. Understorycanopy relationships in oak woodlands and savannas. Pages 183-190 in N. H. Pillsbury, J. Verner, W. D. Tieje, technical coordinators. Proceedings of a symposium on oak woodlands: ecology, management, and urban interface issues, 19-22 March 1996, San Luis Obispo, $C A$. General Technical Report PSW-GTR-160. Pacific Southwest Research Station, Forest Service, U.S. Department of Agriculture, Albany, California, USA.

Fryxell, J. M. 1991. Forage quality and aggregation by large herbivores. American Naturalist 138:478-498.

Fryxell, J. M., M. Hazell, L. Borger, B. Dalziel, D. Haydon, J. Morales, T. McIntosh, and R. Rosatte. 2008. Multiple movement modes by large herbivores at multiple spatiotemporal scales. Proceedings of the National Academy of Sciences 105:19114-19119.

Gaillard, J. M., M. Festa-Bianchet, N. G. Yoccoz, A. Loison, and C. Toïgo. 2000. Temporal variation in fitness components and population dynamics of large herbivores. Annual Review of Ecology, Evolution, and Systematics 31:367-393.

Gaillard, J. M., M. Hebblewhite, A. Loison, M. Fuller, R. Powell, M. Basille, and B. Van Moorter. 2010. Habitat-performance relationships: finding the right metric at a given spatial scale. Philosophical Transactions of the Royal Society B: Biological Sciences 365:2255-2265.

Garshelis, D. L. 2000. Delusions in habitat evaluation: measuring use, selection, and importance. Pages 111-164 in L. Boitani and T. K. Fuller, editors. Research techniques in animal ecology: controversies and consequences. Columbia University Press, New York, New York, USA.

Gaylord, A. J. 2013. Ungulate activity classification: calibrating activity monitor GPS collars for Rocky Mountain elk, mule deer, and cattle. Thesis, Oregon State University, Corvallis, USA.

Gaylord, A. J., D. M. Sanchez, and J. Van Sickle. 2016. Choosing sampling interval durations for remotely classifying Rocky Mountain elk behavior. Journal of Fish and Wildlife Management 7:213-221.

Gillies, C. S., M. Hebblewhite, S. E. Nielsen, M. A. Krawchuk, C. L. Aldridge, J. L. Frair, D. J. Saher, C. E. Stevens, and C. L. Jerde. 2006. Application of random effects to the study of resource selection by animals. Journal of Animal Ecology 75:887-898.

Gillingham, M. P. 2004. Ecology of black-tailed deer in north coastal environments. Pages 39-47 in J. Gaston, T. E. Golumbia, J. L. Martin, and S. T. Sharpe, editors. Lessons from the Islands: Proceedings from the Research Group on Introduced Species 2002 Conference, Queen Charlotte City, British Columbia. Canadian Wildlife Service, Environment Canada, Ottawa, Canada.

Gillingham, M. P., K. L. Parker, and T. A. Hanley. 1997. Forage intake by black-tailed deer in a natural environment: bout dynamics. Canadian Journal of Zoology 75:1118-1128. 
Godvik, I. M. R., L. E. Loe, J. O. Vik, V. Veiberg, R. Langvatn, and A. Mysterud. 2009. Temporal scales, trade-offs, and functional responses in red deer habitat selection. Ecology 90:699-710.

Hanley, T. A. 1982. The nutritional basis for food selection by ungulates. Journal of Range Management 35:146-151.

Hanley, T. A. 1983. Black-tailed deer, elk, and forest edge in a western Cascades watershed. Journal of Wildlife Management 47:237-242.

Hebblewhite, M., and E. Merrill. 2008. Modelling wildlife-human relationships for social species with mixed-effects resource selection models. Journal of Applied Ecology 45:834-844.

Heffelfinger, J., and T. A. Messmer. 2003. Introduction. Pages 1-11 in J. C. deVos, M. R. Conover, and N. E. Headrick, editors. Mule deer conservation: issues and management strategies. Berryman Institute Press, Utah State University, Logan, USA.

Horn, B. K. P. 1981. Hill shading and the reflectance map. Proceedings of the Institute of Electrical and Electronics Engineers 69:14-47.

Johnson, D. H. 1980. The comparison of usage and availability measurements for evaluating resource preference. Ecology 61:65-71.

Johnson, C. J., K. L. Parker, and D. C. Heard. 2001. Foraging across a variable landscape: behavioral decisions made by woodland caribou at multiple spatial scales. Oecologia 127:590-602.

Kie, J. G., and R. T. Bowyer. 1999. Sexual segregation in white-tailed deer: density-dependent changes in use of space, habitat selection, and dietary niche. Journal of Mammalogy 80:1004-1020.

Kie, J. G., R. T. Bowyer, M. C. Nicholson, B. B. Boroski, and E. R. Loft. 2002. Landscape heterogeneity at differing scales: effects on spatial distribution of mule deer. Ecology 83:530-544.

Krebs, J. R. 1980. Optimal foraging, predation risk and territory defence. Ardea 68:83-90.

Kremsater, L. L., and F. L. Bunnell. 1992. Testing responses to forest edges: the example of black-tailed deer. Canadian Journal of Zoology 70:2426-2435.

Kuhfeld, R. C., D. C. Bowden, and D. L. Schrupp. 1988. Habitat selection and activity patterns of female mule deer in the Front Range, Colorado. Journal of Range Management 41:515-522.

Leblond, M., J. Frair, D. Fortin, C. Dussault, J. P. Ouellet, and R. Courtois. 2011. Assessing the influence of resource covariates at multiple spatial scales: an application to forest-dwelling caribou faced with intensive human activity. Landscape Ecology 26:1433-1446.

Leopold, A. 1933. The conservation ethic. Journal of Forestry 31:634-643.

Long, R. A., J. G. Kie, R. T. Bowyer, and M. A. Hurley. 2009a. Resource selection and movements by female mule deer Odocoileus hemionus: effects of reproductive stage. Wildlife Biology 15:288-298.

Long, R. A., J. D. Muir, J. L. Rachlow, and J. G. Kie. 2009b. A comparison of two modeling approaches for evaluating wildlife-habitat relationships. Journal of Wildlife Management 73:294-302.

Lorimer, C. G., J. W. Chapman, and W. D. Lambert. 1994. Tall understory vegetation as a factor in the poor development of oak seedlings beneath mature stands. Journal of Ecology 82:227-237.

Löttker, P., A. Rummel, M. Traube, A. Stache, P. Šustr, J. Müller, and M. Heurich. 2009. New possibilities of observing animal behaviour from a distance using activity sensors in GPS-collars: an attempt to calibrate remotely collected activity data with direct behavioural observations in red deer Cervus elaphus. Wildlife Biology 15:425-434.

Lounsberry, Z. T., T. D. Forrester, M. T. Olegario, J. L. Brazeal, H. U. Wittmer, and B. N. Sacks. 2015. Estimating sex-specific abundance in fawning areas of a high-density Columbian black-tailed deer population using fecal DNA. Journal of Wildlife Management 79:39-49

Manly, B., L. McDonald, D. Thomas, T. McDonald, and W. Erickson. 2002. Resource selection by animals: statistical analysis and design for field studies. Kluwer, Nordrecht, The Netherlands.

Marescot, L., T. D. Forrester, D. S. Casady, and H. U. Wittmer. 2015. Using multistate capture-mark-recapture models to quantify effects of predation on age-specific survival and population growth in black-tailed deer. Population Ecology 57:185-197.

Mauffette, Y., and W. C. Oechel. 1989. Seasonal variation in leaf chemistry of the coast live oak Quercus agrifolia and implications for the California oak moth Phryganidia californica. Oecologia 79:439-445.

Mayor, S. J., D. C. Schneider, J. A. Schaefer, and S. P. Mahoney. 2009. Habitat selection at multiple scales. Ecoscience 16:238-247.

Monteith, K. L., V. C. Bleich, T. R. Stephenson, B. M. Pierce, M. M. Conner, R. W. Klaver, and R. T. Bowyer. 2011. Timing of seasonal migration in mule deer: effects of climate, plant phenology, and lifehistory characteristics. Ecosphere 2:1-34.

Morris, D. W. 2003. How can we apply theories of habitat selection to wildlife conservation and management? Wildlife Research 30:303-319.

Mysterud, A., and E. Østbye. 1999. Cover as a habitat element for temperate ungulates: effects on habitat selection and demography. Wildlife Society Bulletin 27:385-394.

Parker, K. L., P. S. Barboza, and M. P. Gillingham. 2009. Nutrition integrates environmental responses of ungulates. Functional Ecology 23:57-69.

Parker, K. L., C. T. Robbins, and T. A. Hanley. 1984. Energy expenditures for locomotion by mule deer and elk. Journal of Wildlife Management 48:474-488.

Pierce, B. M., R. T. Bowyer, and V. C. Bleich. 2004. Habitat selection by mule deer: forage benefits or risk of predation? Journal of Wildlife Management 68:533-541.

Prugh, L. R., and C. D. Golden. 2014. Does moonlight increase predation risk? Meta-analysis reveals divergent responses of nocturnal mammals to lunar cycles. Journal of Animal Ecology 83:504-514.

R Development Core Team. 2014. R: a language and environment for statistical computing. R Foundation for Statistical Computing, Vienna, Austria.

Rettie, W. J., and F. Messier. 2000. Hierarchical habitat selection by woodland caribou: its relationship to limiting factors. Ecography $23: 466-478$

Riley, S. J., and A. R. Dood. 1984. Summer movements, home range, habitat use, and behavior of mule deer fawns. Journal of Wildlife Management 48:1302-1310

Roever, C., H. Beyer, M. Chase, and R. Aarde. 2014. The pitfalls of ignoring behaviour when quantifying habitat selection. Diversity and Distributions 20:322-333.

Rosenzweig, M. L. 1991. Habitat selection and population interactions: the search for mechanism. American Naturalist 137:S5-S28.

Salminen, J.-P., V. Ossipova, J. Loponena, E. Haukiojab, and K. Pihlaja. 2004. Seasonal variation in the content of hydrolyzable tannins, flavonoid glycosides, and proanthocyanidins in oak leaves. Journal of Chemical Ecology 30:1693-1711.

Sappington, J. M., K. M. Longshore, and D. B. Thompson. 2007. Quantifying landscape ruggedness for animal habitat analysis: a case study using bighorn sheep in the Mojave Desert. Journal of Wildlife Management 71:1419-1426.

Sawyer, H., R. M. Nielson, F. G. Lindzey, L. Keith, J. H. Powell, and A. A. Abraham. 2007. Habitat selection of Rocky Mountain elk in a nonforested environment. Journal of Wildlife Management 71:868-874.

Sawyer, H., R. M. Nielson, F. Lindzey, and L. L. McDonald. 2006. Winter habitat selection of mule deer before and during development of a natural gas field. Journal of Wildlife Management 70:396-403.

Seaman, D. E., and R. A. Powell. 1996. An evaluation of the accuracy of kernel densitor estimators for home range analysis. Ecology 77:2075-2085.

Senft, R. L., M. B. Coughenour, D. W. Bailey, L. R. Rittenhouse, O. E. Sala, and D. M. Swift. 1987. Large herbivore foraging and ecological hierarchies. BioScience 37:789-799.

Smith, H. D., M. C. Oveson, and C. L. Pritchett. 1986. Characteristics of mule deer beds. Great Basin Naturalist 46:542-546.

Taillon, J., D. G. Sauvé, and S. D. Côté. 2006. The effects of decreasing winter diet quality on foraging behavior and life-history traits of white-tailed deer fawns. Journal of Wildlife Management 70:1445-1454

Van Beest, F. M., A. Mysterud, L. E. Loe, and J. M. Milner. 2010. Forage quantity, quality and depletion as scale-dependent mechanisms driving habitat selection of a large browsing herbivore. Journal of Animal Ecology 79:910-922.

Van Beest, F. M., B. Van Moorter, and J. M. Milner. 2012. Temperaturemediated habitat use and selection by a heat-sensitive northern ungulate. Animal Behaviour 84:723-735.

Van Moorter, B., J. Gaillard, P. D. McLaughlin, D. D, F. Klein, and M. S. Boyce. 2009. Maternal and individual effects in selection of bed sites and their consequences for fawn survival at different spatial scales. Oecologia 159:669-678

Van Soest, P. J. 1994. Nutritional ecology of the ruminant. Cornell University Press, Ithaca, New York, USA. 
Wallmo, O. C. 1981. Mule and black-tailed deer in North America. University of Nebraska Press, Lincoln, USA.

Wilmers, C. C., B. Nickel, C. M. Bryce, J. A. Smith, R. E. Wheat, and V. Yovovich. 2015. The golden age of bio-logging: how animalborne sensors are advancing the frontiers of ecology. Ecology 96:1741-1753.

Xie, Y., K. F. Ahmed, J. M. Allen, A. M. Wilson, and J. A. Silander. 2015. Green-up of deciduous forest communities of northeastern North America in response to climate variation and climate change. Landscape Ecology 30:109-123.
Zuur, A. F., E. N. Ieno, and C. S. Elphick. 2010. A protocol for data exploration to avoid common statistical problems. Methods in Ecology and Evolution 1:3-14.

Associate Editor: Scott McCorquodale.

\section{SUPPORTING INFORMATION}

Additional supporting information may be found in the online version of this article at the publisher's website. 